\title{
Determination of Parking Lots and Pedestrian Way Effects on the Queue Length and Emission Values in the New Campus of Adana Science And Technology University
}

\author{
Anıl Erkan', Gökhan Tüccar²* \\ 1,2Adana Science and Technology University, Turkey
}

\begin{abstract}
In this paper, parking lots and pedestrian way effects on the queue length and emissions in the new campus of Adana Science and Technology University were investigated. Three different parking capacities were compared as 15,10 and no parking lots. Microsimulation software called VISSIM was used to evaluate parking lots and pedestrian way effects. Queue length and vehicular emissions are two main parameters that were analyzed. The simulation results showed that emission values decrease as queue length values decrease. In addition, according to simulation results when 10 parking lots are allowed instead of 15 , queue length has decreased as $6,815 \%$, and emissions (such as $\mathrm{CO}, \mathrm{NOx}$ ) have decreased as 3,86\%. If no parking is allowed instead of 10 parking lots, queue length has decreased as $86,63 \%$, and emissions have decreased as $54,29 \%$.
\end{abstract}

Keywords: VISSIM, Queue Length, Emissions, Parking, Pedestrian Way

\section{INTRODUCTION}

As everyone knows, traffic is one of the biggest problems in metropolises. Design of traffic model is crucial when a new place is build. On the contrary, it is not easy to adopt this design to an old settlement. Modeling provides determination of errors in advance. There are many advantages of modeling [1]. One of them is to identify emission values. Many studies have been made to reduce emissions recently [2]. Vehicle situations in traffic have effects on emission types and values. When vehicles are too fast, $\mathrm{CO}$ emission increases (in Gasoline engine). If vehicles wait so much in traffic, $\mathrm{CO}$, $\mathrm{NOx}$ and VOc values increase. Excess amount (>750 ppm) of CO can have fatal effects on human health. Inhalation of air with a volumetric concentration of $0.3 \%$ carbon monoxide can result in death within 30 minutes. Pure $\mathrm{NO}_{2}$ is a poisonous, reddish-brown gas with penetrating odor. $\mathrm{NO}_{2}$ can react with moisture present in the atmosphere to form nitric acid, causes direct damage to materials. It is also responsible to the formation of smog (photochemical oxidants), which are the most damaging to human health.Volatile organic compound is called "VOc". Fuel evaporation creates VOc emissions and this emission type is harmful for ozone layer [3].

Some types of simulation programs can be used for modeling, such as Vissim, Aimsum and Paramics. Vissim is a widely used one among these programs. Gai (2005) introduces the modules, function and application field of Vissim [4].

VISSIM which is used in this study is a microscopic time step and behaviour based simulation model. Flow of pedestrians can be modelled as well as traffic by the use of VISSIM. VISSIM can demonstrate public and private traffic and it enables evaluation of various alternatives for transportation planning. $2 \mathrm{D}$ and $3 \mathrm{D}$ visualizations are also available in this program. There are many advantages of VISSIM over other micro-simulation software. VISSIM has the ability to model the interaction between various modes of traffic, it also has ability to generate vehicles randomly and flexibility in modeling complex geometries [5]. VISSIM has advantages in terms of ease of use and does not require cumbersome coding [6]

Parking lots and pedestrian way effects on the traffic situation can be simulated in the Vissim.

Muhammed and Robert (2009) provide a method for including pedestrians in Vissim model. Their work demonstrates the feasibility of modeling vehicle-pedestrian interactions in a realistic manner [7].

Don, Xiaokuan and Chao (2013) simulated some different scenarios to Beijing Central District area in China.They use travel time, travel speed, queue length and delay as evaluation indicators to conduct comparison [8].

\footnotetext{
${ }^{*}$ Corresponding authour

Email: gtuccar@yahoo.com (G. Tuccar)

$\S$ This paper was presented in the IMSEC-2016
} 
$\mathrm{Pu}$, Long and Yang (2004), compared average vehicle delay times under varying traffic signals and then selected the optimal traffic signalization timing for the ideal delay period [9].

Keay, Jastia, Munoza et al. (2009) select 1425 drivers aged 67-87 living in Salisbury, Maryland, to conduct a study of driving to identify visual and cognitive predictors for older drivers' failure to stop at stop signs [10].

Similar procedure was done for Adana Science and Technology University (ASTU) campus. Three types of scenarios were investigated as 15,10 and no parking lots. Pedestrian way was placed in front of these parking lots. Thus, the interaction between pedestrian-vehicle and traffic situation was determined.

\section{METHODOLOGY}

Vissim is a microscopic simulation tool usually used in traffic regulation. This program allows the best option to be implemented by simulating the intensity of traffic according to varying conditions [6].

There is a requirement for arrangement of traffic model of the new campus of Adana Science and Technology University due to daily increase in university population. Especially, vehicle and pedestrian intensities are expected to increase during lecture hours. Therefore, parking capacity, parking area and pedestrian way are important factors for decreasing queue lengths, emissions and fuel consumption. By regulating these factors, time efficiency can be increased in the traffic, thus, stress on the drivers and air pollutions can be eliminated.

New campus plan of ASTU is shown in Figure 1. In first stage, campus area will not be built completely. Only rector building, deanery building, administrative offices, engineering faculty classes, their laboratories and main cafeteria are planned to be constructed.

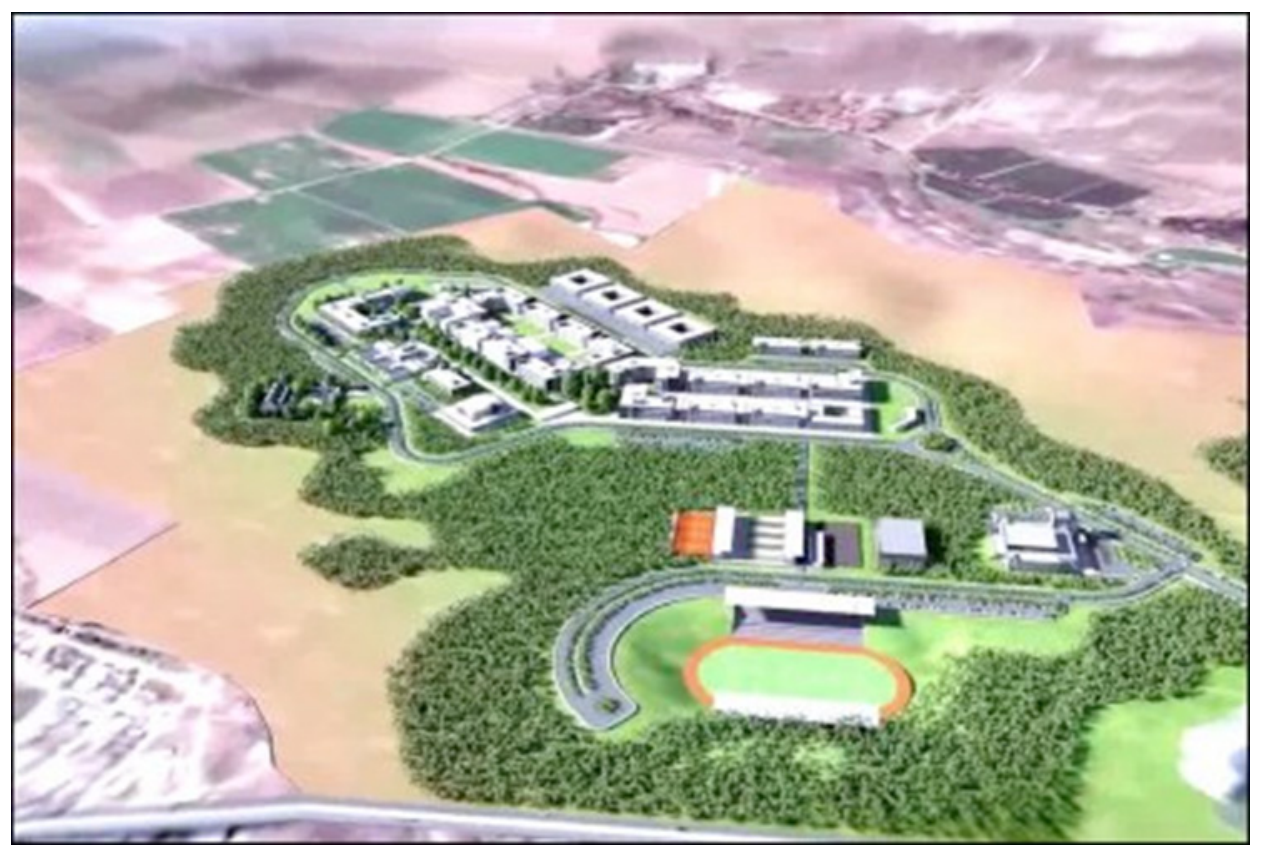

Figure 1: Adana Science and Technology University (ASTU) campus pla

Case study at the campus is shown in Figure 2. Parking lots and pedestrian way were inserted on this area. The vehicle intensity of 400/hour and pedestrian intensity of 200 /hour were chosen in this study which is an estimated value during day hours. As a result, to prevent complexity in traffic in front of the main buildings of the campus, three types of allowable parking lots were investigated as shown in Figure 3[a-c] and model was tested for 30 minutes time period ( between 08:30 a.m - 09:00 a.m). 


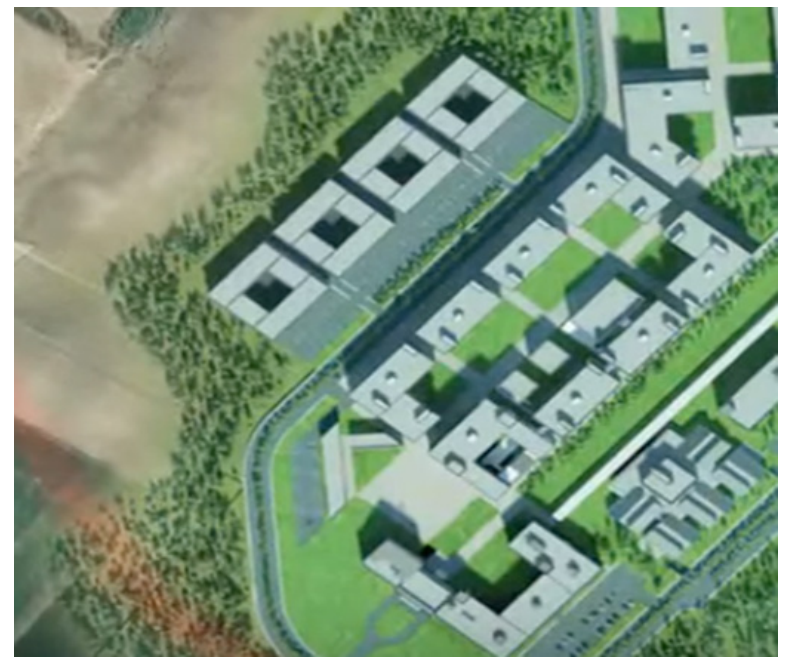

Figure 2: Case study at campus

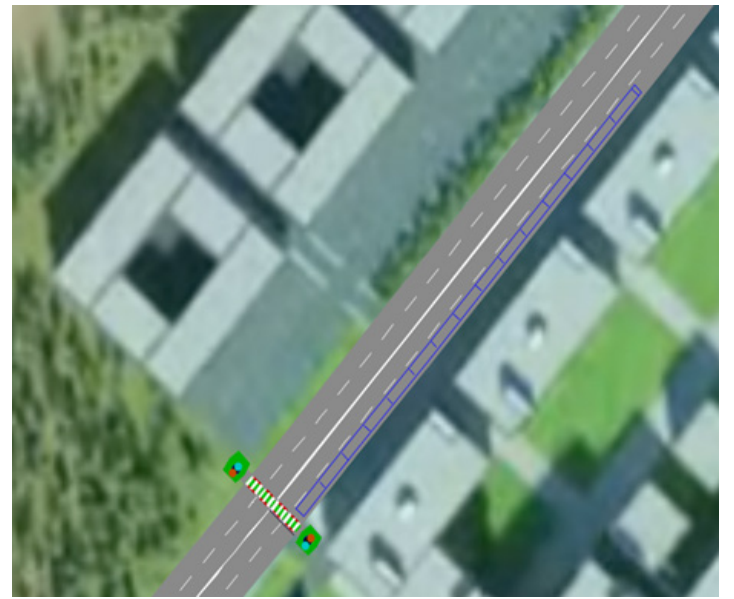

a)15 Parking Lots

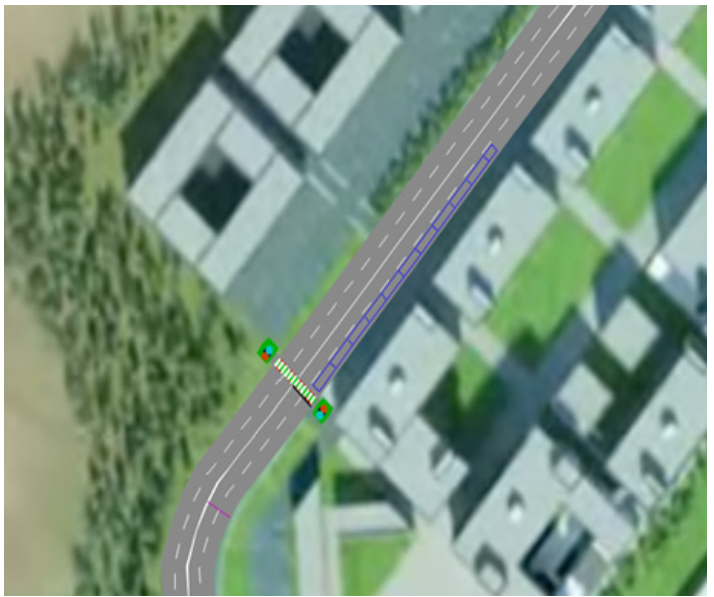

b) 10 Parking Lots

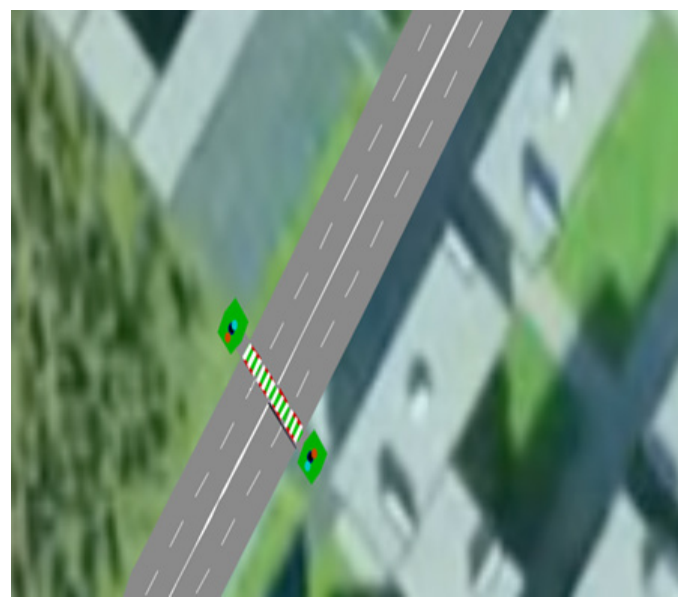

c) No Parking

Figure $3[\mathrm{a}-\mathrm{c}]$ : Modeling of the parking lots and pedestrian way in the Vissim software

$3 \mathrm{D}$ model of pedestrians and vehicles is shown in Figure 4. In this model, parking lots and pedestrian way effects on the queue length can be seen clearly. Some necessary inputs that were entered to the software are shown in Table 1. 


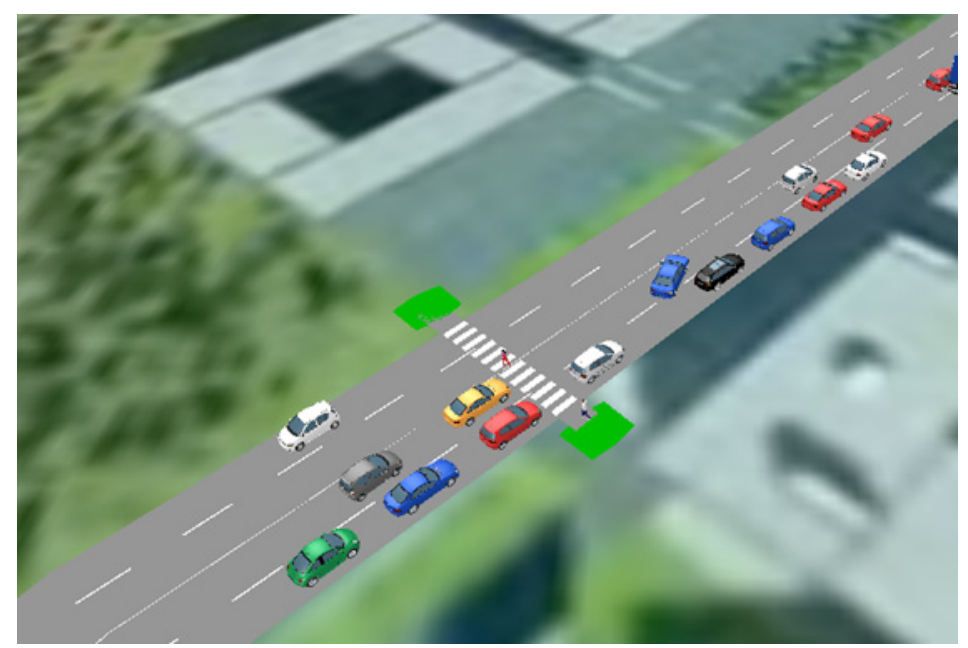

Figure $4: 3 \mathrm{D}$ Modeling of the system

Table 1 Some input data used in VISSIM

\begin{tabular}{|c|c|}
\hline Input Data & Quantity \\
\hline Parking Capacity & 10,15 and No Parking \\
\hline Parking Percentage & $30 \mathrm{~km} / \mathrm{s}$ \\
\hline Max. Speed & 400 vehicles/hour \\
\hline Vehicle Input & 200 pedestrians $/$ hour \\
\hline Pedestrian Input & 30 minutes \\
\hline Duration & 2 minutes \\
\hline Time Interval & \\
\hline
\end{tabular}

\section{RESULTS AND DISCUSSION}

During the time period between 08:30 and 09:00, traffic situation was observed. The high traffic intensity makes this time period more reasonable for investigation. Vehicle types are arranged randomly for vehicles that flow along the way. When 15 parking lots are inserted to the way, max. queue length has occurred as $46,64 \mathrm{~m}$. This result was $27,16 \mathrm{~m}$ when 10 parking lots are inserted to the way. If the parking lots are removed from the way (no parking case), max. queue length has occurred as $13,52 \mathrm{~m}$. In this case, the only factor that affects queue length is pedestrian effect because node counter was placed front of the pedestrian way.

Average queue lengths within 2 minutes time intervals obtained for different parking lots are shown Figure 5. If parking capacity was decreased from 15 to 10 , average queue length has decreased as 6,81\%. If parking wasn't allowed, with only pedestrian way effects, average queue length has decreased as $86,63 \%$.

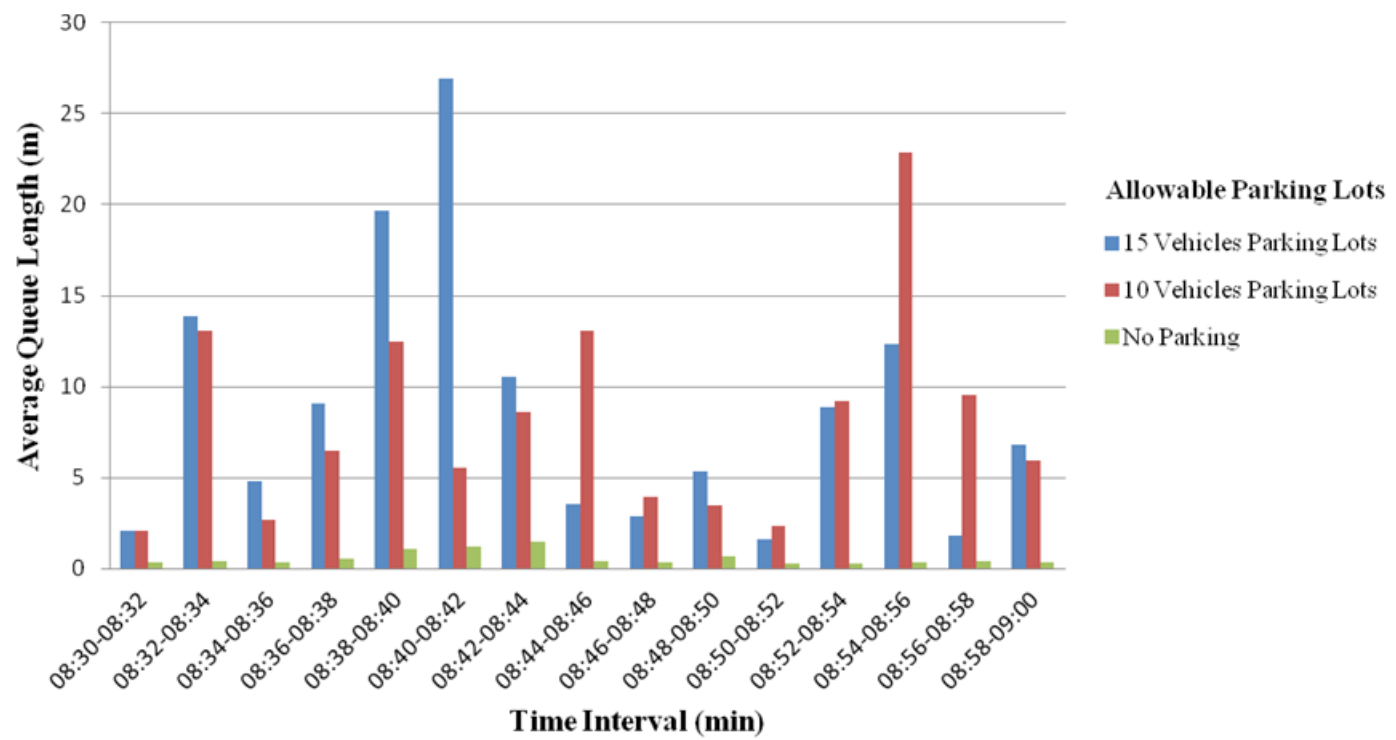

Figure 5 : Comparision of average queue length results 
As a result of combustion fuels exhaust emissions gasses are formed and these gases include toxic pollutants such as carbon monoxide $(\mathrm{CO})$, carbon dioxide $\left(\mathrm{CO}_{2}\right)$, oxides of nitrogen $(\mathrm{NOx})$. These gasses are toxic and harmful for human healt and the nature [11]. Exhaust emission values obtained for different allowable parking lots are shown in Figure 6 and 7. In figure 6, NOx emissions values are represented. According to the results vehicular emissions and queue lengths increase with increasing number of allowable parking lots. There is 3,86\% fall in emission values (NOx, CO) when 10 parking lots are allowed instead of 15 parking lots. When no parking is allowed instead of 10 parking lots, there was $54,29 \%$ decrease.

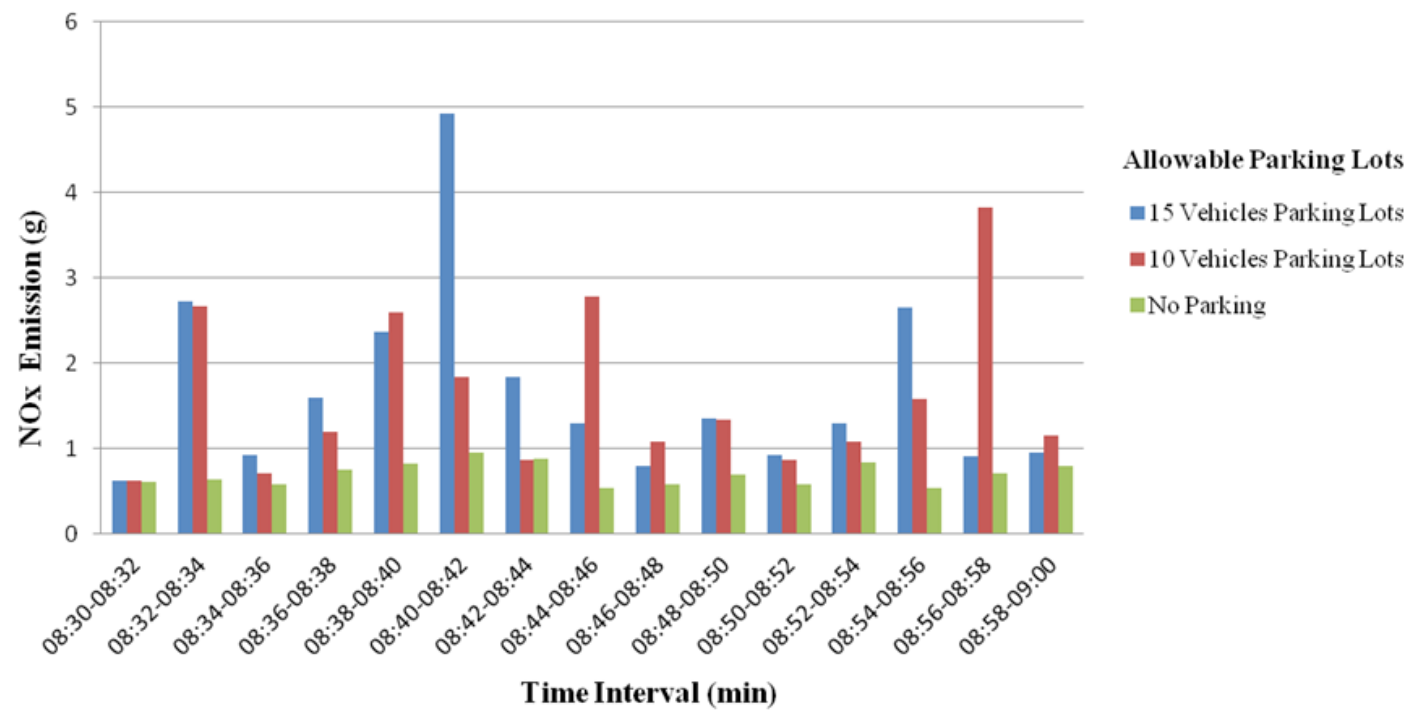

Figure 6 : Comparision of $\mathrm{NOx}$ emission results

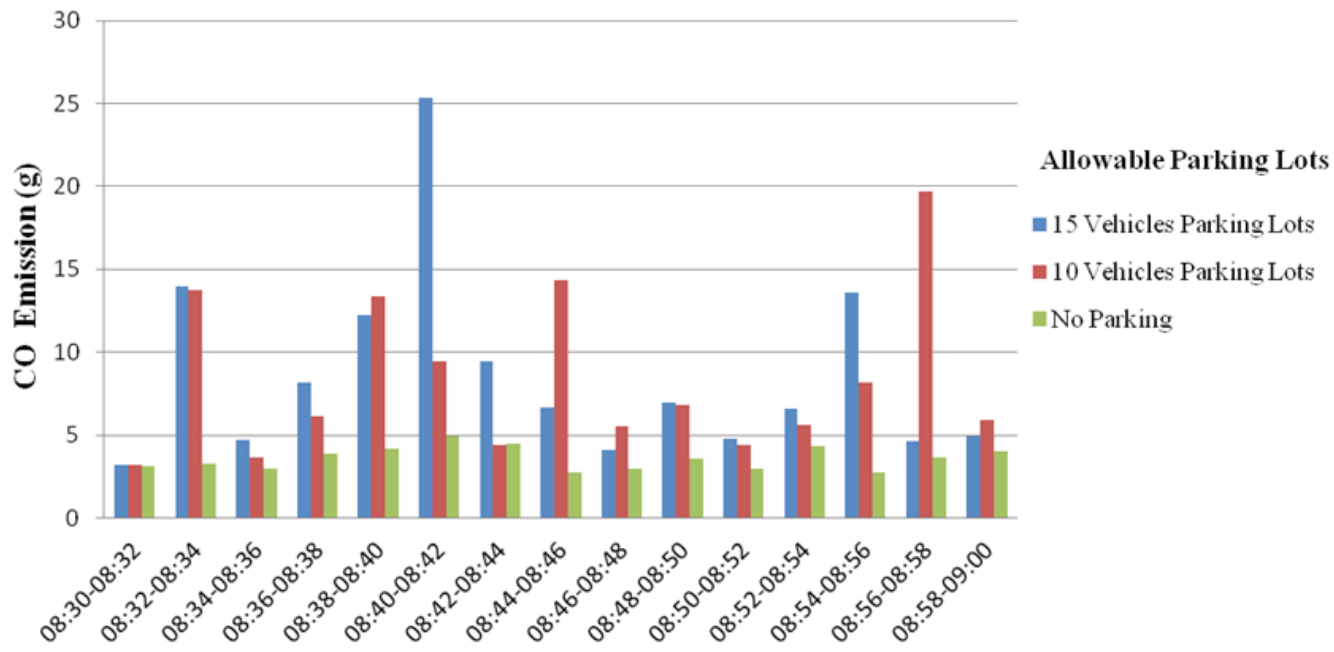

Time Interval (min)

Figure 7 : Comparing $\mathrm{CO}$ emission results within 2 minutes of time periods

Total fuel consumption values are shown in Table 2 . Fuel consumption is directly related with queue length . If parking lots are decreased from 15 to 10 , fuel consumption has decreased by $3,886 \%$. If no parking is allowed instead of 10 parking lots, this value decreases as 54,29\%; therefore, fuel will be utilized more efficiently.

Table 2 Total fuel consumption values

\begin{tabular}{|c|c|}
\hline Allowable Parking Lots & Fuel Consumption \\
\hline 15 & 7,01 (liters) \\
\hline 10 & 6,74 (liters) \\
\hline No Parking & 2,93 (liters) \\
\hline
\end{tabular}




\section{CONCLUSION}

Traffic regulation is one of the main problems that occur in crowded cities. Traffic simulation programs are frequently used to regulate traffic in recent times. Therefore, effects of number of allowable parking lots on traffic intensity has been examined this study.

Parking lots and pedestrian way simulation results showed that queue length directly affects all relative things.

It has been found that with increasing density of the allowable parking lots; queue lengths, harmful exhaust emissions and fuel consumption are significantly reduced.

To prevent problem created by parking lots that is placed on side of the way and pedestrian way the number of new style of parking areas and footbridges in critical points needs to be increased.

\section{REFERENCES}

[1] PTV.VISSIM 5.40-03 User Manual. PTV Planning Transport Verkehr AG, Karlsruhe, 2012.

[2] Bambode, K., Gajghate, V., (2014). Traffic Signal Optimization for Important Routes In Nagpur City: A Review. International Journal of Emerging Technology and Advanced Engineering, vol. 2 no. 4, pp.511-514.

[3] Akay M.E., Akgüngör A.P. (2008). Modeling of Traffic Signals Syncronisation Effect For Vehicle Emission Reduction. Journal of Polytechnic, vol.11 no.1, pp.51-56.

[4] Gai Chunying (2005). Microscopic Simulation System VISSIM and Its Application to Road and Transportation. Highway, no.8, pp.118-121.

[5] Siddharth S., Ramadurai G. (2013). Calibration of VISSIM for Indian Heterogeneous Traffic Conditions. Procedia - Social and Behavioral Sciences, vol: 104, pp.380 - 389.

[6] Ratrout, T.N., Rahman S.M. (2008). A Comperative Analysis of Currently used Microscopic and Macroscopic Traffic Simulation Software. The Arabian Journal for Science and Engineering, vol. 34, no: $1 \mathrm{~B}$.

[7] Ishaque M.M. and Noland R. B. (2009). Pedestrian and Vehicle Flow Calibration in Multimodal Traffic Microsimulation. Journal of Transportation Engineering, pp.338-348.

[8] Lin D. , Yang X., Gao. C. (2013). VISSIM-based Simulation Analysis on Road Network of CBD in Beijing, China. 13 ${ }^{\text {th }}$ COTA International Conference of Transportation Professionals, pp.461-472.

[9] Pu, W., Long, L. and Yang, X. (2004). Traffic signal warrant study for stop-controlled intersections. Urban Traffic, vol.2, no.3, pp.7-9.

[10] Keay, L., Jastia, S., Munoz,a B., Kathleen, Turanoa A. , Cynthia, A. Munroc, Donald, D. Duncand (2009). Urban and rural differences in older drivers' failure to stop at stop signs. Accident Analysis and Prevention, vol.41, no.5, pp.995-1000.

[11] Yıldızhan, Ş., Uludamar, E., Çalık, A., Dede, G. , Ozcanlı, M.(2017). Fuel properties, performance and emission characterization of waste cooking oil (WCO) in a variable compression ratio (VCR) diesel engine. European Mechanical Science, vol. 1(2), pp. 56-62 